\title{
The computational fluid dynamics performance analysis of horizontal axis wind turbine
}

\author{
Naji Abdullah Mezaal ${ }^{1}$, Osintsev K. V. ${ }^{2}$, Alyukov S.V. ${ }^{3}$ \\ ${ }^{1}$ Master in Heat and Power Engineering, South Ural State University, Russian Federation \\ ${ }^{2,3}$ Departement of Heat and Power Engineering, South Ural State University, Russian Federation
}

\begin{tabular}{l}
\hline Article Info \\
\hline Article history: \\
Received Nov 29, 2018 \\
Revised Mar 1, 2019 \\
Accepted Mar 12, 2019 \\
\hline
\end{tabular}

\section{Keywords:}

Airfoils (S818, S825, S826)

CFD

Horizontal axis Wind Turbine

Modelling and Simulation

Power coefficient (Cp)

WT_Perf analysis

\begin{abstract}
Computational fluid dynamics (CFD) simulations were performed in the present study using ANSYS Fluent 18.0, a commercially available CFD package, to characterize the behaviour of the new HAWT. Static threedimensional CFD simulations were conducted. The static torque characteristics of the turbine and the simplicity of design highlight its suitability for the GE $1.5 x$ le turbine. The major factor for generating the power through the HAWT is the velocity of air and the position of the blade angle in the HAWT blade assembly. The paper presents the effect of The blade is $43.2 \mathrm{~m}$ length and starts with a cylindrical shape at the root then transitions to the airfoils S818, S825 and S826 for the root, body and tip respectively. This blade also has pitch to vary as a function of radius, giving it a twist and the pitch angle at the blade tip is 4 degrees. This blade was created to be similar in size to a GE $1.5 x$ le turbine by Cornell University. In addition, note that to represent the blade being connected to a hub, the blade root is offset from the axis of rotation by 1 meter. The hub is not included in our model. The experimental analysis of GE $1.5 x$ xe turbine, so that possible the result of CFD analysis can be compared with theoretical calculations. CFD workbench of ANSYS is used to carry out the virtue simulation and testing. The software generated test results are validated through the experimental readings. Through this obtainable result will be in the means of maximum constant power generation from HAWT.
\end{abstract}

Copyright (C) 2019 Institute of Advanced Engineering and Science. All rights reserved.

\section{Corresponding Author:}

Naji Abdullah Mezaal,

Master in Heat and Power Engineering,

Al Wihda, Baghdad, 10075, Iraq.

Email: naji.allamee@gmail.com

\section{INTRODUCTION}

The focus on Renewable Energy Resources has increased significantly in the recent years in the wake of growing environmental pollution, rising energy demand and depleting fossil fuel resources. Different sources of renewable energy include biomass, solar, geothermal, hydroelectric, and wind. Among these resources, the wind turned out to be a cheaper alternative energy resource, and, therefore, extensive research efforts were made to improve the technology of electricity generation by wind. The world has enormous potential of wind energy that can be utilized for electricity generation. Currently, large scale HAWTs are not economically attractive; however, they offer energy solutions for remote places away from the main distribution lines and places where large wind farms cannot be installed due to environmental concerns and small scale dispersed generation units are preferred. In this paper, the blade was created to be similar in size to a GE 1.5xle turbine that used to validate the CFD results, where the experimental data of GE 1.5xle turbine can be compared with theoretical calculations and CFD analysis of this paper. In the following sections we will show the purpose of this paper. 
This study considers the deformation due to aerodynamic loading of a wind turbine blade by performing a steady-state 1-way FSI (Fluid-Structure Interaction) analysis. This study uses ANSYS Fluent 18.0 to develop the aerodynamics loading on the blade. The blade is 43.2 meters long, the blade is made out of an orthotropic composite material, it has a varying thickness and it has a spar inside the blade for structural rigidity. These specs, which are important for the FEA simulation.

The main objective of this paper is to analyze the flow field around the horizontal axis wind turbine by numerically solving the governing equations using a finite-volume method and Reynolds's Averaged Navier-Stokes (RANS) approach [3]. Upstream and downstream wake visualization in terms of $\mathrm{x}, \mathrm{y}$ and zvelocities are in the scope of the paper. Also, tangential velocity at the tip of the blade will be plotted and compared with theoretical results. The other objective of the paper works is to determine the efficiency and power extracted by wind turbines [4]. The project is structured as follows:

a. Modelling the one-third of the wind turbine rotor by means of $120^{\circ}$ periodicity. Select the geometry of the blade shape by Block Element Modifier (BEM) designing techniques.

b. Create the 3-D model of the blade profile and blade for the simulation in SOLID-WORK.

c. Create computational domain for flow field analysis and generate high quality mesh.

d. Create the cavity model for the cavity analysis for the CFD analysis and simulation.

e. Calculate the power extracted by the turbine.

f. Comparison of the software simulation data and theoretical calculations of GE 1.5xle turbine.

g. Validation of the result will be done.

In this section of the study, the blade geometry is imported, a mesh is created around the blade and the fluent solver is then used to find the aerodynamics loading on the blade, the fluid streamlines and the torque generated. We will use air at standard conditions (15-degree Celsius). Its density is $1.225 \mathrm{~kg} / \mathrm{m}^{3}$ and its viscosity is $1.7894 \mathrm{e}-05 \mathrm{~kg} /(\mathrm{m} * \mathrm{~s})$. Using periodicity, we will simulate the flow around one blade and extrapolate the solution to two more blades in order to visualize the results for a 3-blade rotor.

Analysis of the blade in the analytical mode gives useful results of the first pass about stresses and moments that are useful in determining the basic requirements for strength and materials. This type of analytical analysis, though useful, is insufficient to properly evaluate the full wind turbine blade. Accordingly, we sought to use finite element analysis to more accurately capture the loads and stresses generated on the blade geometry by particular loading scenarios. This computational method allows for much greater flexibility in testing out various loads and blade geometries, allowing for an iterative approach to developing our turbine blade. First, we began by selecting our airfoils. We decided to use the NREL S-series of airfoil as described in (Malcolm and Hansen 2006). These airfoils are in general somewhat thicker than the types typically seen on airplanes due to structural concerns, and are largely insensitive to roughness. As such, they are well suited for turbine blades. Figure 1 shows turbine blade airfoils (S818, S825, S826).

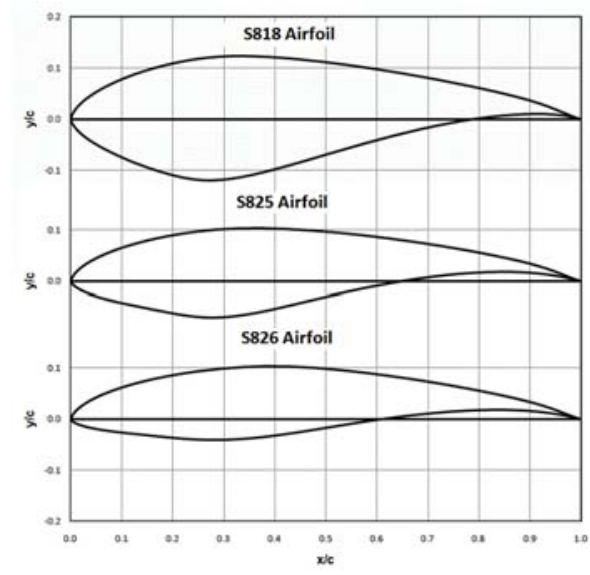

Figure 1. Turbine blade airfoils (S818, S825, S826)

The beginning of the blade is the circular hub section. This circular root transitions into the S818 airfoil, which then transitions to the S825 airfoil, which then transitions into the S826 airfoil used at the tip. All geometry of the blade, including the length of the twist, span and chord, was determined using the WT_Perf analysis and can be seen below in Table 2 [1-2].

The computational fluid dynamics performance analysis of horizontal axis wind ... (Naji Abdullah Mezaal) 


\begin{tabular}{cccccc}
\multicolumn{5}{c}{ Table 1. Turbine blade geometry } \\
\hline Relm $(\%$ span $)$ & Span $(\mathrm{m})$ & Twist $(\mathrm{deg})$ & Chord $(\%$ span $)$ & Chord $(\mathrm{m})$ & Airfoil \\
\hline 0.075 & 3.09375 & 42 & 0.06140 & 2.5328 & \\
0.125 & 5.15625 & 32 & 0.06826 & 2.8157 & \\
0.175 & 7.21875 & 23 & 0.07452 & 3.0740 & \\
0.225 & 9.28125 & 15 & 0.07782 & 3.2101 & S818 \\
0.275 & 11.34375 & 11.5 & 0.07543 & 3.1115 & \\
0.325 & 13.40625 & 8.2 & 0.07188 & 2.9651 & \\
0.375 & 15.46875 & 7 & 0.06832 & 2.8182 & \\
0.425 & 17.53125 & 6 & 0.06479 & 2.6726 & \\
0.475 & 19.59375 & 5 & 0.06126 & 2.5270 & \\
0.525 & 21.65625 & 4 & 0.05771 & 2.3805 & \\
0.575 & 23.71875 & 4.15 & 0.05415 & 2.2337 & \\
0.625 & 25.78125 & 3.85 & 0.05062 & 1.9416 & \\
0.675 & 27.84375 & 3.25 & 0.04707 & 1.7985 & \\
0.725 & 29.90625 & 2.75 & 0.04360 & 1.6599 & \\
0.775 & 31.96875 & 1.25 & 0.04024 & 1.5279 & \\
0.825 & 34.03125 & 0.75 & 0.03704 & 1.3963 & \\
0.875 & 36.09375 & 0.55 & 0.03385 & 1.1331 & \\
0.925 & 38.15625 & 0.85 & 0.03066 & 1 & \\
0.975 & 40.21875 & 0.05 & 0.02747 & & \\
1 & 41.25 & 0 & 0.02424 & & \\
\hline
\end{tabular}

With the given geometry of the blade, we starte the process of creating the blade for our FEA model. Although we can simulate and analyze the full wing using ANSYS, so we decided to model the blade using the SolidWorks CAD package instead. Because we can import geometry directly from SolidWorks to ANSYS, this seemed to be the most effective way to manage the creation of the blade [1-2].

\section{MATHEMATICAL MODEL}

The turbulent wind flows towards the negative $\mathrm{z}$-direction at $12 \mathrm{~m} / \mathrm{s}$, which is a typical rated wind speed for a turbine this size. This incoming flow assumed to make the blade rotate at an angular velocity of $2.22 \mathrm{rad} / \mathrm{s}$ about the $\mathrm{z}$-axis (the blade is thus spinning clockwise when looking at it from the front, like most real wind turbines). The tip speed ratio (TSR) (the ratio of the blade tip velocity to the incoming wind velocity) is therefore equal to 8 which is a reasonable value for a large wind turbine. Note that to represent the blade being connected to a hub, the blade root is offset from the axis of rotation by 1 meter. The hub is not included in our model.

\subsection{Governing equations}

The governing equations are the continuity and Navier-Stokes equations. These equations are written in a frame of reference rotating with the blade. This has the advantage of making our simulation not require a moving mesh to account for the rotation of the blade [5]. The equations that we will use look as follows:

Conservation of mass:

$$
\frac{\partial \rho}{\sigma t}+\nabla \rho v_{2}=0
$$

Conservation of Momentum (Navier-Stokes):

$$
\nabla\left(\rho v_{r} v_{r}\right)+\rho\left(2 \varpi \times v_{r}+\varpi \times \varpi \times r\right)=-\nabla p+\nabla \overline{\mathbf{T}} r
$$

Where;

$V_{\mathrm{r}}$ is the relative velocity (the velocity viewed from the moving frame) and $\varpi$ is the angular velocity [5].

Note the additional terms for the Coriolis force $\left(2 \varpi \times v_{r}\right)$ and the centripetal acceleration $(\varpi \times \varpi \times r)$ in the Navier-Stokes equations. In Fluent, we'll turn on the additional terms for a moving frame of reference and input $\varpi=-2.22 \mathrm{rad} / \mathrm{sec}$. Important: We use the Reynolds Averaged form of continuity and momentum and use the SST k-omega turbulence model to close the equation set [6]-[7].

\subsection{Boundary conditions}

We model only $1 / 3$ of the full domain using periodicity assumptions:

Int J Pow Elec \& Dri Syst, Vol. 10, No. 2, June 2019 : 1072 - 1080 


$$
\vec{v}\left(r_{1}, \theta\right)=\vec{v}\left(r_{1}, \theta_{1}-120^{\circ} n\right)
$$

Figure 2 shows periodicity assumptions.

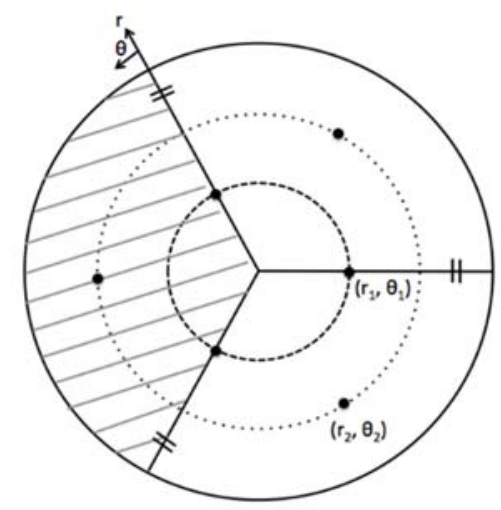

Figure 2. Periodicity assumptions

$$
\begin{aligned}
\vec{v}\left(r_{1}, \theta\right) & =\vec{v}\left(r_{1}, \theta_{1}-120^{\circ} n\right) \quad \text { For } n=1,2,3 \ldots \\
& =\vec{v}\left(r_{1}, 240^{\circ}-120^{\circ}(1)\right)=\vec{v}\left(r_{1}, 120^{\circ}\right) \\
& =\vec{v}\left(r_{1}, 240^{\circ}-120^{\circ}(2)\right)=\vec{v}\left(r_{1}, 0^{\circ}\right) \\
\vec{v}\left(r_{2}, \theta\right) & =\vec{v}\left(r_{2}, \theta_{2}-120^{\circ} n\right) \quad \text { For } n=1,2,3 \ldots \\
& =\vec{v}\left(r_{2}, 180^{\circ}-120^{\circ}(1)\right)=\vec{v}\left(r_{2}, 60^{\circ}\right)
\end{aligned}
$$

This therefore proves that the velocity distribution at theta of 0 and 120 degrees are the same. If we denote theta_1 to represent one of the periodic boundaries for the $1 / 3$ domain and theta- 2 being the other boundary, then

$$
\begin{aligned}
\vec{v}\left(r_{i}, \theta_{1}\right) & =\vec{v}\left(r_{i}, \theta_{2}\right) \\
& v\left(r_{i}, \theta_{1}\right)=v\left(r_{i}, \theta_{2}\right)
\end{aligned}
$$

The boundary conditions on the fluid domain are as follow:

Inlet: Velocity of $12 \mathrm{~m} / \mathrm{s}$ with turbulent intensity of $5 \%$ and turbulent viscosity ratio of 10 , Outlet: Pressure of 1 atm, Blade: No-slip, Side Boundaries: Periodic [3].

\subsection{Numerical solution procedure in ANSYS}

FLUENT converts these differential equations into a set of algebraic equations. Inverting these algebraic equations gives the value of ( $u, v, w, p, k$, and omega) at the cell centers. Everything else is derived from the cell centres values (post-processing). In our mesh, we'll have around 10000,000 cells. The total number of unknowns and hence algebraic equations is:

$10,000,000 \cdot 6=60$ million

This huge set of algebraic equations is inverted through an iterative process. The matrix to be inverted is huge but sparse. In FLUENT, we will use the pressure-based solver.

\subsection{Hand-calculations of expected results}

According to the specification sheet of the turbine GE 1.5 xle wind, one simple hand-calculation that we can do now before even starting our simulation is to find theoretical wind velocity at the tip. We can then

The computational fluid dynamics performance analysis of horizontal axis wind ... (Naji Abdullah Mezaal) 
later compare our answer with what we get from our simulation to verify that they agree. The velocity (v), on the blade should follow the formula:

$$
v=r \cdot \omega
$$

Plugging in our angular velocity of $2.22 \mathrm{rad} / \mathrm{s}$ and using the blade length of 43.2 meters plus 1 meter to account for the distance from the root to the hub, we get $44.2 \mathrm{~m}$.

$$
\begin{aligned}
\mathrm{v} & =2.22 \cdot 44.2 \\
& =98.12 \mathrm{~m} / \mathrm{s}
\end{aligned}
$$

Additionally, by using the simple one-dimensional momentum theory, we can estimate the power coefficient which is the fraction of harnessed power to total power in the wind for the given turbine swept area. This analysis uses the following assumptions:

a. The flow is steady, homogenous and incompressible.

b. There is no frictional drag.

c. There is an infinite number of blades.

d. There is uniform thrust over the disc or rotor area.

e. The wake is non-rotating.

f. The static pressure far upstream and downstream of the rotor is equal to the undisturbed ambient pressure.

According to this blade is meant to resemble GE 1.5 xle wind turbine blade [8]. The specification sheet of this turbine states the rated power of this turbine to be $1.5 \mathrm{MW}$, the rated wind speed to be $11.5 \mathrm{~m} / \mathrm{s}$ and the rotor diameter to be $82.5 \mathrm{~m}$. A powe and power coefficient [9] is then defined as:

$$
\begin{aligned}
& P=T \cdot \omega \\
& C_{p}=\frac{P_{\text {rated }}}{P_{\text {wind }}}=\frac{P_{\text {rated }}}{0.5 \rho A V_{\text {rated }}^{3}} \\
& C_{p}=\frac{1500,000}{0.5 \cdot(1.225) \cdot\left(\frac{\pi\left(82.5^{2}\right)}{4}\right) \cdot\left(11.5^{3}\right)}=0.3
\end{aligned}
$$

The resulting power coefficient of 0.3 it is very reasonable. We will compare it to power coefficient obtained from the simulation in the Verification and Conclusion section.

\subsection{Betz equation and criterion}

The Betz Equation deals with the wind speed upstream $V_{0}$ and the downstream $V_{3}$ wind speed of the turbine. The value of the Betz limit suggests that a wind turbine can be extracted at most 59.3 percent of energy in an undisturbed wind speed stream [11], it can be defined as:

Betz coefficient $=C_{p}=\frac{16}{27}=0.592593=59.3 \%$

Lanchester-Betz-Joukowsky limit [10] shows that the actual turbine cannot extract more than 59.3\% of the power in an undisturbed tube of air of the same as shown in Figure 3 [4-11].

Int J Pow Elec \& Dri Syst, Vol. 10, No. 2, June 2019 : 1072 - 1080 


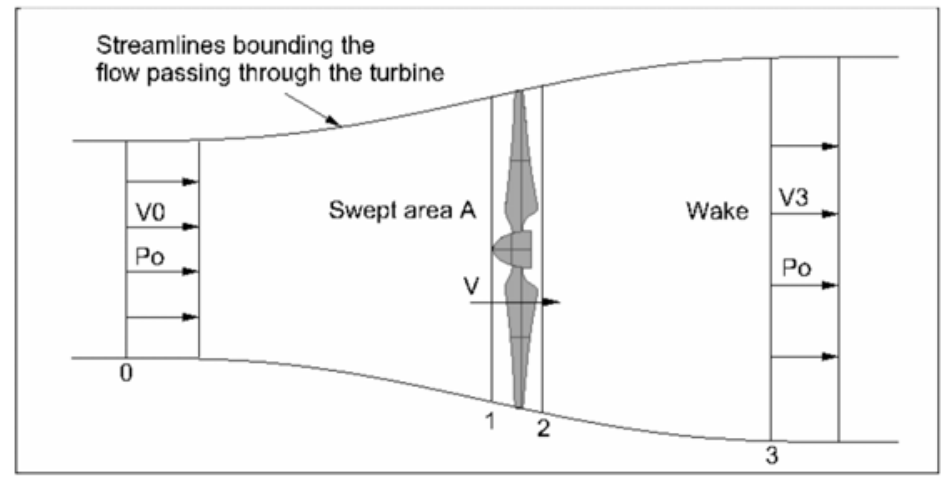

Figure 3. Control volume for the idealized actuator-disk analysis

\subsection{Power coefficient}

The power generated by the kinetic energy of a free flowing wind stream is shown in the Figure 3, where is defined as the ratio of the power extracted by the wind turbine relative to the energy available in the wind stream. Power coefficient $(\mathrm{Cp})$, represented as extracted power over the total power, it can be expressed by the induction factor (a) as:

$$
C_{p}=4 a(1-a)^{2}
$$

Where (a) is Induction factor, the fractional decrease in wind velocity between the free stream and rotor plane can be expressed in terms of an axial induction factor, a:

$$
a=\frac{v_{0}-v}{v_{0}}
$$

Where, $V$ is the velocity at the disk and it is defined by:

$$
v=\frac{1}{2}\left(v_{0}+v_{3}\right)
$$

$V_{0}$ and $V_{3}$ are free stream and downstream velocities respectively. The amount of axial induction factor determines the amount of power extracted by turbine [4].

\section{RESEARCH METHOD}

\subsection{Geometry and mesh generation}

In the following section, we will create our geometry and the blade volume from the fluid geometry as shown in Figure 4. As we mentioned in boundary condition part as showed in Figure 2 periodicity assumptions.

Grid generation is often considered as the most time consuming part of CFD simulation. We start off by naming various faces of our geometry for later use in FLUENT and to make surface body referencing much easier when creating our mesh as shown in Figure 5. After several attempts to mesh the geometry we have been obtained on this good number of mesh, our geometry has a high quality mesh around 10884336 elements as shown in Figure 6, this is considering a very fine enough to obtain a sufficiently accurate solution. We are applying specifying some global mesh settings which means that these settings will be applied to the whole mesh altogether. After applying controls to the whole mesh, we now apply mesh settings to specific areas of our geometry.

The computational fluid dynamics performance analysis of horizontal axis wind ... (Naji Abdullah Mezaal) 


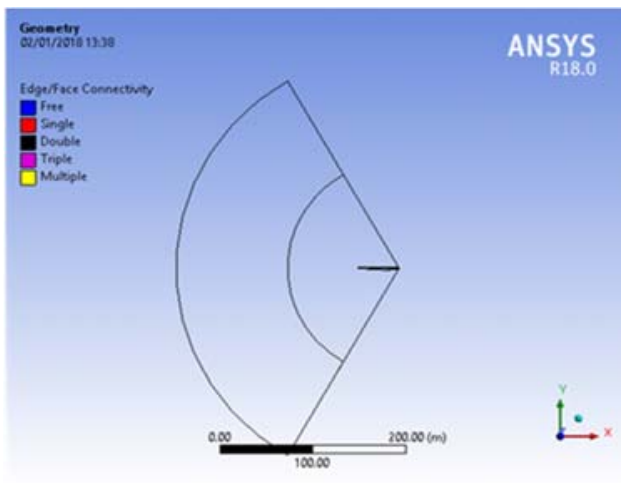

Figure 4. Wind turbine blade Geometry

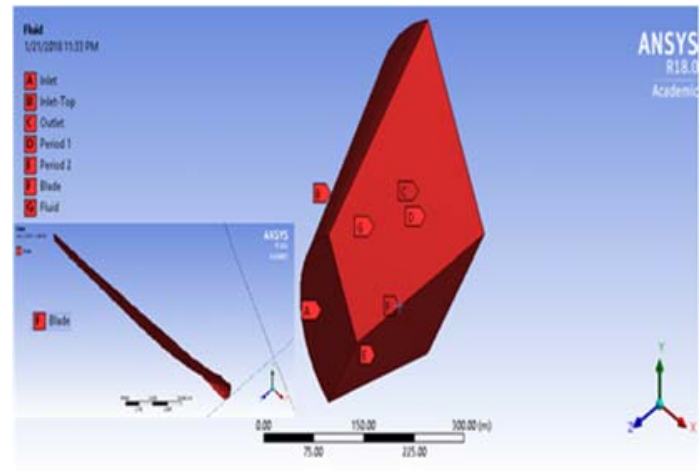

Figure 5. Final Fluid domain with various faces of geometry

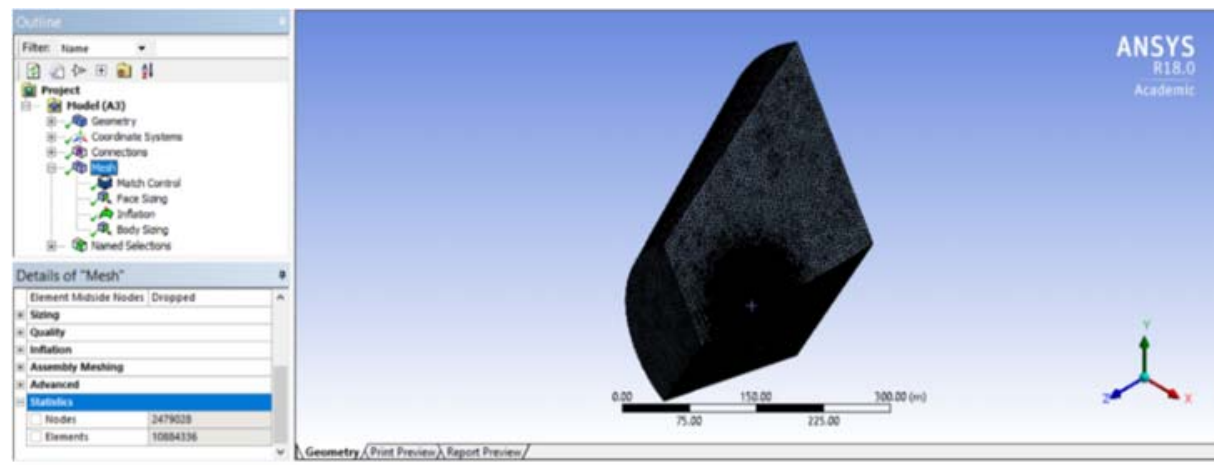

Figure 6. Mesh geometry generation with number of mesh elements in ANSYS Fluent

\section{RESULTS AND ANALYSIS}

\subsection{Blade velocity}

In CFD-Post for the numerical results. We will enable the visualization of a full 3-blade rotor as shown in Figure 7. First, a hand-calculation is did based on the classical aerodynamic theory in order to find the theoretical wind velocity at the tip. This data is comparing with the value of the velocity obtained by ANSYS. Figure 7 and illustrate that the local wind turbine blade velocity increases with radius because of the rotation of the blades. The velocity of the tip, which is the highest velocity, it is around $98.14 \mathrm{~m} / \mathrm{s}$, the same value as equation.

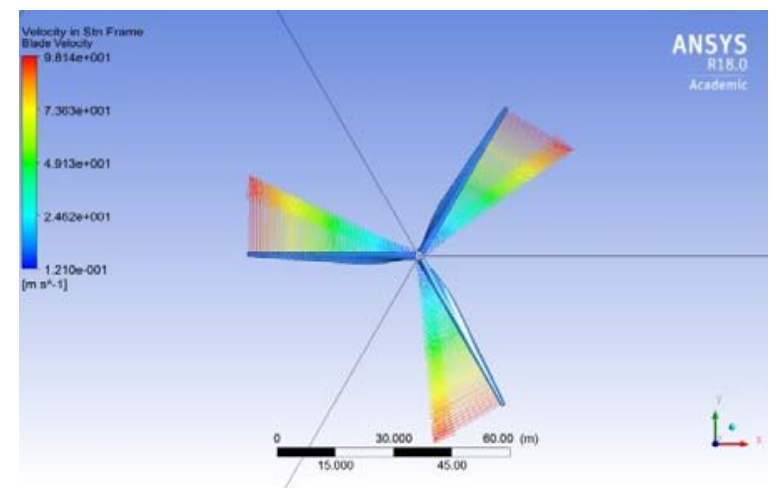

Figure 7. Blade velocity 


\subsection{Velocity streamlines}

Wind velocity streamline shows the velocity of the fluid domain around the three wind turbine blades, see Figure 8 shows visualize the flow around the turbine using velocity streamlines:

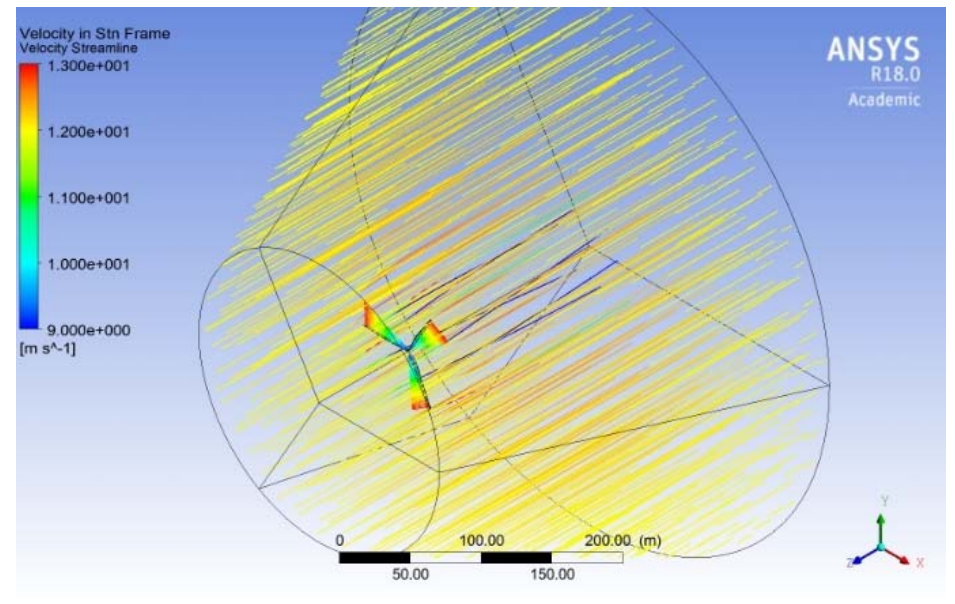

Figure 8. Blade velocity streamlines

Note that the legend bar in the above picture presents a color graduation from blue, which is the lowest velocity, until red. Inlet section $\left(V_{0}\right)$ has yellow color so it is $12 \mathrm{~m} / \mathrm{s}$, as it was mentioned earlier. The color blue in the streamlines means that when the airflow passes the blades $\left(V_{3}\right)$ so it is $10 \mathrm{~m} / \mathrm{s}$, it suffers a slowing down and the velocity decreases. Clearly, an acceleration of the flow around the wake is represented by red color. All these features match the mass conservation and momentum theory.

\section{VERIFICATION}

From the Figure 8 and by applying (6) to (8) for obtaining the efficiency (Cp) of the turbines is the implementation of the Actuator Disk Theory. Free stream velocity $V_{0}$ and downstream velocity $V_{3}$, are obtained from CFD and (6) to (8) will again result the power coefficient (Cp) is 0.298.

The value of the velocity obtained by ANSYS Figure 7 illustrate that the local wind turbine blade velocity increases with radius because of the rotation of the blades. The velocity of the tip, which is the highest velocity, it is around $98.14 \mathrm{~m} / \mathrm{s}$, the same value as (3). The Torque is a force that turns or rotates the wind turbine and it is equal to the force multiplied by distance. This means that so longer blades are, more torque can generate. The value that we have been obtained from our CFD analysis for one blade is 421910 n.m. and by applying (4) we have power is $936.64 \mathrm{~kW}$. Now we can compare the CFD results and mathematical calculations with the experimental data of GE1.5 xle turbine in the Table 2.

Table 2. Comparison of Results

\begin{tabular}{cccc}
\hline Parameter & $\begin{array}{c}\text { Theoretical } \\
\text { calculations }\end{array}$ & GE1.5 xle turbine & CFD analysis \\
\hline Velocity $(\mathrm{v}) \mathrm{m} / \mathrm{s}$ & 98.12 & 97 & 98.14 \\
Power coefficient $\left(C_{p}\right)$ & 0.59 & 0.265 & 0.298 \\
\hline
\end{tabular}

\section{CONCLUSION}

In the present investigation, the aerodynamic efficiency of the horizontal axis wind turbine using computational methods of fluid dynamics is studied. The obtained CFD results are compared with the mathematical calculation and experimental data of the GE1.5 xle turbine. This study has demonstrated that the CFD methods confirm the experimental results and can be used to optimize and confirmation the shape Specifications of the turbine. According to the results of this research, it can be concluded that the power coefficient of the turbine is actually matches to the theoretical results as demonstrated.

The computational fluid dynamics performance analysis of horizontal axis wind ... (Naji Abdullah Mezaal) 


\section{REFERENCES}

[1] C. Phelps, J. Singleton, "Wind Turbine Blade Design. Cornell University," Sibley School of Engineering, pp. 2-14, 2013.

[2] Tukesh Sinhg Thakur, Brijesh Patel, "Structural Analysis of a Composite Wind Turbine Blade to optimize its Constructional Parameters using a FEA Software," IJSRD-International Journal for Scientific Research \& Development. Vol. 3. No. 4pp. 572-576, Nov. 2016.

[3] Acker, T., Hand, M., "Aerodynamic Performance of the NREL Unsteady Aerodynamics Experiment (Phase IV) Twisted Rotor," Prepared for the 37th AIAA Aerospace Sciences Meeting and Exhibit, Reno, 10pp. 211-221,Jan. 1999.

[4] Armen Sargsyan, "Simulation and modeling of flow field around a horizontal axis wind turbine (HAWT) using RANS method," Florida Atlantic University, 8pp. 7-15, 2010

[5] Fluent, ANSYS FLUENT 12.0 Theory Guide, ANSYS Inc., April 2009, Sections 18.1.1 and 18.1.2.

[6] Fluent, ANSYS FLUENT 12.0, Tutorial 9-11-12-23-28-29, Turbulence and Discrete Phase Modeling.

[7] Bardina, J. E., Huang, P. G. and Coakley, T.J., "Turbulence Modeling validation, testing, and Development," NASA Technical Memorandum 110446, April 1997.

[8] GE Energy 1.5xle - Manufacturers and turbines - Online access - The Wind Power, RMT, Inc.| North Coast Wind \& Power LLC.

[9] Burton T, Sharpe D, Jenkins N, Bossanyi E,"Wind Energy Handbook," John Wiley \& Sons,Chichester,UK, pp.4547, 2001.

[10] Kuik, G.A.M., "The Lanchester-Betz-Joukowsky Limit, Wind Energy," 10pp. 289-291, 10, 2007.

[11] Magdi Ragheb and Adam M. Ragheb. "Wind Turbines Theory-The Betz Equation and Optimal Rotor Tip Speed Ratio," INTECH open sciences, 21pp ,2-22, July 5, 2011.

[12] Yuqiao Zhen, Rong Zhen Zhao, Hong Liu "Mode Analysis of Horizontal Axis Wind Turbine Blades," TELKOMNIKA Indonesian Journal of Electrical Engineering, Vol.12, pp. $1212 \sim 1216$, February 2014.

[13] Shuangwen Sheng, Ryan O'Connor "Reliability of Wind Turbines," Wind Energy Engineering, 2017, DOI 10.1016/B978-0-12-809451-8.00015-1

[14] Diniar Mungil Kurniawati, Dominicus Danardono Dwi Prija Tjahjana, Budi Santoso "Experimental investigation on performance of crossflow wind turbine as effect of blades number," The 1st International Conference And Exhibition on Powder Technology Indonesia (ICePTi) 2017, AIP Conference Proceedings 1931(1):030045, DOI $10.1063 / 1.5024104$

[15] Ilham Satrio Utomo, Dominicus Danardono Dwi Prija Tjahjana, Syamsul Hadi "Experimental studies of Savonius wind turbines with variations sizes and fin numbers towards performance," The 1st International Conference And Exhibition on Powder Technology Indonesia (ICePTi) 2017, AIP Conference Proceedings 1931(1):030041, DOI $10.1063 / 1.5024100$

[16] Yoga Arob Wicaksono, Dominicus Danardono Dwi Prija Tjahjana, Syamsul Hadi "Influence of omni-directional guide vane on the performance of cross-flow rotor for urban wind energy," The 1st International Conference And Exhibition on Powder Technology Indonesia (ICePTi) 2017, AIP Conference Proceedings 1931(1):030040, DOI $10.1063 / 1.5024099$

[17] Dominicus Danardono Dwi Prija Tjahjana, Arnold Thamrin Halomoan, Andreas Wibowo, Dwi Aries Himawanto, Yoga Arob Wicaksono "Wind potential assessment in urban area of Surakarta city," The 1st International Conference And Exhibition on Powder Technology Indonesia (ICePTi) 2017, AIP Conference Proceedings 1931(1):030070, DOI 10.1063/1.5024129

[18] Patrick A.B. James, AbuBakr S Bahaj "Small-Scale Wind Turbines," Wind Energy Engineering, 2017, DOI 10.1016/B978-0-12-809451-8.00019-9

[19] Adam M. Ragheb, Michael S Selig "Multielement Airfoils for Wind Turbines," Wind Energy Engineering, 2017, DOI 10.1016/B978-0-12-809451-8.00011-4

[20] Loiy Al-Ghussain, Onur Taylan, Murat Fahrioglu "Sizing of a Photovoltaic-Wind-Oil Shale Hybrid System: Case Analysis in Jordan,” 2018, Journal of Solar Energy Engineering. Vol. 140, no 1. 011002, DOI 10.1115/1.4038048

Int J Pow Elec \& Dri Syst, Vol. 10, No. 2, June 2019 : 1072 - 1080 